\title{
The Significance of miR-34a Expression in Endometrial Carcinogenesis: Correlation With Expression of p16 and Ki-67 Proteins in Endometrial Cancers
}

\author{
Yoon Sung Choi, Kyung Eun Lee \\ Department of Clinical Laboratory Science, College of Health Sciences, Catholic University of Pusan, Busan, Korea
}

\begin{abstract}
Background: A microRNA, miR-34a, plays a key role in inhibiting cellular transformation and carcinogenesis by controlling cell cycle regulation and cell proliferation in various human tumors. However, miR-34a has rarely been reported in endometrial cancer research in Korea. This study was undertaken to analyze miR-34a expression in simple endometrial hyperplasia and endometrial cancer, and to evaluate the relationship between expression of miR-34a and p16 and Ki-67 proteins in endometrial cancers.

Methods: A retrospective study was carried out on 66 formalin-fixed, paraffin-embedded tissues with simple endometrial hyperplasia (31 cases) and endometrial cancer (35 cases) patients. These were analyzed for miR-34a expression by quantitative real-time PCR , and the expression of p16 and Ki-67 proteins in endometrial cancers was evaluated by immunohistochemistry.

Results: The miR-34a expression level was lower in endometrial cancer tissues $(-0.71 \pm 3.90)$ than in simple endometrial hyperplasia tissues $(2.68 \pm 8.62)$. The endometrial hyperplasia tissues showed underexpression of miR-34a in 13 of the 31 cases $(41.9 \%)$ while the endometrial cancer tissues showed underexpression of miR-34a in 24 of 35 cases (68.6\%). Thus, miR-34a was significantly underexpressed in endometrial cancer tissues when compared endometrial hyperplasia tissues $(P=0.046)$. Overexpression of p16 was detected in 25 (71.4\%) and Ki-67 immunoreactivity was detected in 27 (77.1\%) of the 35 endometrial cancers. Although not statistically significant, the frequency of 16 and Ki-67 overexpression tended to be lower in the cases with miR-34a underexpression than in cases with miR-34a overexpression.

Conclusions: These findings suggest that underexpression of miR-34a might be involved in endometrial carcinogenesis. Further studies are needed to define the relationship between miR-34a expression and tissue specific protein expression.
\end{abstract}

(J Cancer Prev 2015;20:268-274)

Key Words: miR-34a, p16, Ki-67, Simple endometrial hyperplasia, Endometrial cancer

\section{INTRODUCTION}

Endometrial cancer, the seventh most common cancer in women worldwide, has shown a marked increase in incidence in Korea. ${ }^{1}$ The causes of endometrial cancer include hormonal imbalances, obesity, low fertility rate, late menopause, increases in postmenopausal bleeding, and anovulation. The focus on causes of endometrial cancer and susceptibility of the endometrium to carcinogenesis has already yielded much information; however, the detailed network of events leading from estrogen stimulation to tumor development remains to be clarified. $^{2}$

Epigenetic changes in gene expression through effects on chromatin without DNA mutation, ${ }^{1,3}$ such as microRNA (miRNA, $\mathrm{miR}$ ) regulation, are now receiving attention as causes of cancer. ${ }^{1.3}$ Gene expression mechanisms operating by dysregulation of miR are important for the development of cancer, and changes in gene expression may participate in this mechanism. Many studies have described the dysregulation of miRs in several human cancers. ${ }^{4}$ However, studies of miRs in the development of

Received October 8, 2015, Revised October 30, 2015, Accepted October 30, 2015

Correspondence to: Kyung Eun Lee

Department of Clinical Laboratory Science, College of Health Sciences, Catholic University of Pusan, 57 Oryundae-ro, Geumjeong-gu, Busan 46252 , Korea Tel: +82-51-510-0562, Fax: +82-51-510-0568, E-mail: kelee@cup.ac.kr, ORCID: Kyung Eun Lee, http://orcid.org/0000-0001-9543-4159

Copyright (C) 2015 Korean Society of Cancer Prevention

(c) This is an Open Access article distributed under the terms of the Creative Commons Attribution Non-Commercial License (http://creativecommons.org/licenses/by-nc/4.0) which permits unrestricted non-commercial use, distribution, and reproduction in any medium, provided the original work is properly cited. 
endometrial cancer are lacking, particularly in Asia. The miRs are a class of single-stranded non-coding RNA molecules, about 21 to 25 nucleotides in length, that are cleaved from 70 to 100 nucleotide hairpin-shaped precursors. ${ }^{5}$ The miRs play important regulatory roles by sequence-specific base pairing on the 3 ' untranslated region (3'UTR) of target messenger RNA (mRNA), which promotes mRNA degradation or inhibits translation. ${ }^{6}$ The miRs may function as oncogenes or tumor suppressors in tumor development. They regulate mRNA levels through transcriptional and post-transcriptional mechanisms, with the best-known mechanism being RNA interference, which occurs posttranscriptionally. ${ }^{7}$ An involvement of miRs suggested in various biological processes, including cell proliferation, apoptosis, differentiation, and metabolism. ${ }^{8.9}$ The discovery that miR dysregulation is linked to cancer has lead to many studies aimed at describing the relationship between miRs, cancer progression, and metastasis. ${ }^{2}$ Aberrant miR expression is associated with several human diseases, including cancer, cardiovascular disorders, inflammatory diseases and benign or malignant pathologies of the female reproductive tract. ${ }^{10-13}$ The expression of miRs can serve as a biomarker of the outcome of cancer diagnosis ${ }^{14}$ because changes in miR expression are involved in the initiation, progression, and metastasis of human cancer. ${ }^{15,16}$ Most studies have determined miR expression in either normal endometrial tissues or cancer tissues, but the possible involvement of miR expression in endometrial hyperplasia is remains to be established. ${ }^{17}$ One miR, miR-34a, has been identified as a tumor suppressor and is associated with a variety of tumors. Many studies have reported that miR-34a is underexpressed in cervical and breast cancers and, its underexpression plays a key role in cellular transformation and carcinogenesis. ${ }^{3}$ Mounting evidence now demonstrates that p53 can transcriptionally activate the expression of miR-34a to promote cell apoptosis and halt cell growth. ${ }^{18}$ Furthermore, miR-34a is regarded as a key component in the p53 tumor suppressor network. However, the roles of these regulators in pathogenesis are poorly understood. ${ }^{18}$

The putative tumor-suppressor, p16, belongs to a class of cyclin-dependent kinase (CDK) inhibitory proteins. It binds specifically to CDK 4 and inhibits the catalytic activity of the CDK-cyclin D complex, a key regulator of the G1 checkpoint of the cell cycle. ${ }^{19}$ It controls cell cycle proliferation during the G1 phase by inhibiting the ability of cyclin D-cdk4/6 complexes to phosphorylate retinoblastoma protein. ${ }^{20}$ Phosphorylation of an oncoprotein leads to the release of associated proteins, such as E2F, that can activate the genes necessary for cell progression through the G1 phase. ${ }^{20}$ The Ki-67 nuclear antigen expression, an indicator of cell proliferation, has also been evaluated as a prognostic factor of survival in several human cancers, including endometrial carcinoma. ${ }^{21} \mathrm{Ki}-67$ is expressed in all active cell cycle phases, and is a superior marker compared to mitotic counts for the assessment of tumor proliferative activity. ${ }^{22,23}$ Other studies have reported significant correlations between miR expression and the Ki-67 protein expression in breast cancers. ${ }^{24.25}$

Current studies have suggested that dysregulation of miR-34a leads to an increased inhibition of tumor suppressor genes, resulting in increased tumor cell proliferation and inhibition of apoptosis. ${ }^{8.9}$ Other studies have suggested that miR-34a may control multiple cell cycle regulators and cell proliferation. ${ }^{26}$ However, the expression of miR-34a in tissues of endometrial hyperplasia and endometrial cancer has not been studied in patient in Korea. Cell proliferation and cell cycle regulation are important in the endometrium because endometrial hyperplasia can progress to endometrial cancer. The present study was undertaken to analyze miR-34a expression in simple endometrial hyperplasia and endometrial cancer, and to evaluate the relationship between expression of miR-34a and that of p16 and Ki-67 proteins in endometrial cancers.

\section{MATERIALS AND METHODS}

\section{Tissue samples}

A retrospective study was performed on 66 formalin-fixed, paraffin-embedded (FFPE) tissues from simple endometrial hyperplasia (31 cases) and endometrial cancer (35 cases) patients admitted to a local hospital in Busan from 2007 to 2012. The ages of the 66 patients ranged from 24 to 62 years (median age, 46 years). All cancer samples were obtained by endometrial curettage, and histopathologically confirmed; no patients had undergone any preoperative chemotherapy or radiotherapy. The H\&E stained cases were reviewed in each slide to ensure the original diagnosis, which was based on the Inational Federation of Gynecology and Obstetrics classification. Histologic diagnoses were reviewed by independent pathologists.

\section{Deparaffinization of formalin-fixed, paraffin- embedded tissue and total RNA extraction}

Four $10 \mu \mathrm{m}$ thick sections of paraffin block of simple endometrial hyperplasia and endometrial cancer tissues were used for total RNA extraction. The paraffin was removed from the samples by placing them in $1 \mathrm{~mL}$ of $100 \%$ xylene, heating for 3 minutes at $50^{\circ} \mathrm{C}$ to fuse the paraffin, and then centrifuging for 2 
minutes at room temperature at 20,000 $\times g$ to pellet the tissue. After centrifugation, the xylene was discarded and $1 \mathrm{~mL}$ of $100 \%$ ethanol (EtOH) was added. After mixing, the sample was centrifuged at 20,000 $\times g$ for 2 minutes at room temperature and the EtOH was removed. The ethanol washing process was repeated three times, removing as residual $\mathrm{EtOH}$ without disturbing the pellet. Finally, the pellet was air dried for approximately 30 minutes.

The RecoverAll total nucleic acid isolation optimized for FFPE samples kit (Ambion Inc., Austin, TX, USA) was used according to the manufacturer's protocol. The proteins were degraded with 100 to $200 \mu \mathrm{L}$ digestion buffer and $4 \mu \mathrm{L}$ protease, followed by incubation for 15 minutes at $50^{\circ} \mathrm{C}$, and for 15 minutes at $80^{\circ} \mathrm{C}$. The RNA was then isolated by adding $790 \mu \mathrm{L}$ of buffer including absolute ethanol, followed by passage through a purification column. The column was washed twice with a buffer, and DNase treatment was carried out, followed by two additional washings. Finally, RNA was eluted into $60 \mu \mathrm{L}$ of elution buffer from the kit at room temperature according to the manufacturer's instructions. All steps in the preparation and handling of total RNA were performed in hood under RNase-free conditions. The isolated total RNA was stored at $-70^{\circ} \mathrm{C}$ until use.

\section{MicroRNA Taqman reverse transcriptase reaction}

Complementary DNA (cDNA) was synthesized using a microRNA TaqMan reverse transcription kit and triplicate TaqMan MicroRNA assays (Applied Biosystems, Foster City, CA, USA) according to the manufacturer's recommendations. A $5 \mu \mathrm{L}$ sample of total RNA was used for reverse transcriptase (RT), using stem-loop RT primers for each miR. For each reaction, $1.5 \mu \mathrm{L}$ of RT buffer, $0.15 \mu \mathrm{L}$ of $100 \mathrm{mM}$ dNTP, $1 \mu \mathrm{L}$ of RT, $0.186 \mu \mathrm{L}$ of RNase inhibitor and $3 \mu \mathrm{L}$ of RT primer were mixed. Purified water was added to reach a final volume of $15 \mu \mathrm{L}$. The cDNA synthesis reaction by real-time-PCR was performed at $16^{\circ} \mathrm{C}$ for 30 minutes, $42^{\circ} \mathrm{C}$ for 30 minutes, and $85^{\circ} \mathrm{C}$ for 5 minutes.

\section{Quantitative real-time PCR Taqman assay}

The quantitative real-time (qRT)-PCR of cDNA obtained from miR was performed with TaqMan universal PCR master mix and TaqMan human MicroRNA assays (Applied Biosystems) using a real-time PCR for thermal cycling and fluorescence detection. Real-time PCR amplification of miRNA was performed in a reaction mix containing $10 \mu \mathrm{L}$ of master mix, $1.33 \mu \mathrm{L}$ of template cDNA, $1 \mu \mathrm{L}$ of $20 \times$ primers, and $7.67 \mu \mathrm{L}$ of distilled water to give a final volume of $20 \mu \mathrm{L}$ for each sample. The reaction mixture was incubated in a strip at 95 for 10 minutes, and 40 cycles of $95^{\circ} \mathrm{C}$ for
15 seconds and $60^{\circ} \mathrm{C}$ for 1 minute for real-time PCR. The U6 small nuclear 2 (RNU6b) was used to normalize the input of total small RNA. Absolute quantification for each miR as well as RNU6b was performed using a generated standard curve and expression of each $\mathrm{miR}$ was presented as the ratio between miR and RNU6b expression. The relative expression level of each miR-34a was measured using the $\Delta \mathrm{Ct}$ method and the following formula: $\Delta \mathrm{Ct}$ $=\mathrm{Ct}(\mathrm{miR}-34 \mathrm{a})-\mathrm{Ct}(\mathrm{RNU6b})$, where Ct represents the threshold cycle number.

\section{Immunohistochemical analysis}

Immunohistochemical studies on $\mathrm{p} 16$ and $\mathrm{Ki}-67$ were performed on FFPE, $4 \mu \mathrm{m}$ thick tissue section using the avidinbiotin-peroxidase complex method. The sections were deparaffinized through a series of xylene baths, and rehydrated in a graded alcohol series. The immunoreactivity was enhanced by microwave antigen retrieval performed at $750 \mathrm{~W}$ for 30 minutes in Tris-EDTA buffer ( $\mathrm{pH}$ 9.0). Endogenous peroxidase activity was blocked with $5 \%$ hydrogen peroxidase for 10 minutes and the samples were incubated with primary antibody for 1 hour at room temperature. The primary antibody was a mouse monoclonal antibody directed against p16 (Santa Cruz Biotechnology, Santa Cruz, CA, USA) and Ki-67 (Lab Vision, Fremont, CA, USA), used in a 1:100 dilution. The secondary antibody was used for an envision chem kit (DakoCytomation, Carpinteria, CA, USA) at room temperature for 30 minutes. The tissue samples were washed in Tris-buffered saline for 10 minutes and then stained with 3, 3'-diaminobenzidine chromogen and Gill's hematoxylin counterstain.

\section{Interpretation of immunohistochemistry}

All the slides were interpreted without knowledge of any of the clinicopathologic data. Immunoreactivity for $\mathrm{p} 16$ expression was defined by the presence of nuclear and cytoplasmic staining and for Ki-67 expression by the presence of nuclear staining. The immunoreactive tumor cells were categorized into four groups based on their percentage scores: 0 (0\%), 1 (1\%-10\%), 2 (11\%-50\%), and 3 (>50\%). The staining intensity was also classified into four groups: 0 (negative), 1 (weak), 2 (moderate), and 3 (strong). A final score was analyzed for each case by multiplying the percentage and the intensity scores. Finally, tumors with multiplied scores exceeding 3 (i.e., tumors with a moderate and strong intensity of $>10 \%$ of the tumor cells) were recorded as showing positive immunoreactivity to p16 and $\mathrm{Ki}-67$; all the other scores were considered negative. 


\section{Statistical analysis}

Statistical analysis was performed using PASW for Windows Standard ver. 18.0 (IBM Co., Armonk, NY, USA). The Fisher exact test was analyzed to assess the relationship between the expression patterns of miR-34a and, p16, and Ki-67. A $P$-value less than 0.05 was considered statistically significant.

\section{RESULTS}

1. Comparison of the miR-34a expression in simple endometrial hyperplasia and endometrial cancer tissues

We determined the levels of miR-34a expression in different endometrial tissues, by examining the expression of miR-34a in simple endometrial hyperplasia tissues $(n=31)$ and endometrial cancer tissues $(\mathrm{n}=35$ ) by qRT-PCR. The average standard deviations of each $\mathrm{Ct}$ value between the duplicate data for miR-34a indicated that the miR-34a expression level was lower in endometrial cancer tissues $(-0.71 \pm 3.90)$ than in simple endometrial hyperplasia tissues $(2.68 \pm 8.62)$. The endometrial hyperplasia tissues showed underexpression of the miR-34a in 13 of the 31 cases (41.9\%) whereas miR-34a was underexpressed in 24 of the 35 endometrial cancer cases (68.6\%). Thus, miR-34a was significantly underexpressed in endometrial cancer tissues when compared to endometrial hyperplasia tissues $(P=0.046)$ (Table 1 , Fig. 1).

\section{Relationship between expression of miR-34a versus p16 and Ki-67 proteins in endometrial cancers}

Overexpression of p16 was detected in 25 (71.4\%) and Ki-67 immunoreactivity was detected in 27 (77.1\%) of the 35 endometrial cancers (Fig. 2). The p16 overexpression was lower in the miR-34a underexpressing (15/24, 62.5\%) than in the miR-34a overexpressing (10/11, 90.9\%) samples. Ki-67 overexpression was lower in the miR-34a underexpressing (17/24, 70.8\%) than in the miR-34a overexpressing (10/11, 90.9\%) samples (Table 2). Although

Table 1. Comparison of miR-34a expression in simple endometrial hyperplasia and endometrial cancer tissues

\begin{tabular}{lccc}
\hline \multicolumn{1}{c}{ Variable } & $\begin{array}{c}\text { Endometrial } \\
\text { hyperplasia }\end{array}$ & $\begin{array}{c}\text { Endometrial } \\
\text { cancers }\end{array}$ & $P$-value \\
\hline miR-34a & - & - & \\
Underexpression & $13(41.9)$ & $24(68.6)$ & 0.046 \\
Overexpression & $18(58.1)$ & $11(31.4)$ & \\
\hline
\end{tabular}

Values are presented as number (\%). not statistically significant, the frequency of p16 and Ki-67 overexpression tended to be lower in the cases with miR-34a underexpression than with miR-34a overexpression.

\section{DISCUSSION}

The miRs, which are 21 to 25 nucleotide functional RNA molecules, represent a class of short non-coding RNA. They play important regulatory roles through sequence-specific base pairing on the 3'UTR of target mRNA, thereby promoting mRNA degradation or inhibiting translation. ${ }^{6}$ Records of miR dysregulation have been reported in many human diseases, including cancer; ${ }^{27}$ however, the underlying mechanisms leading to human cancer development are not fully understood. Several studies have identified either up-regulated or down-regulated miRs in endometrial tissue samples. ${ }^{17}$ Among these, miR-34 has been reported as affecting cancer and various factors and to act as a tumor suppressor gene. ${ }^{3,26}$ In the present study, underexpression of miR-34a was detected in 13 of the 31 cases (41.9\%) of endometrial hyperplasia and in 24 of 35 cases (68.6\%) of endometrial cancer tissues, indicating that. miR-34a was significantly underexpressed in endometrial cancer compared with endometrial hyperplasia $(P=0.046)$. Other studies have reported decreases in miR-34a expression in pancreatic, breast, ovarian, colorectal, and lung cancer cells. ${ }^{18,28}$ Many studies have detected miR expression in cancer tissues, but miR expression, including miR-34a, in endometrial hyperplasia is largely unreported. ${ }^{17}$ Nevertheless, analysis of miRs in endometrial hyperplasia is important because this is a precancerous lesion that can lead to endometrial carcinogenesis. Therefore, underexpression of miR-34a could be

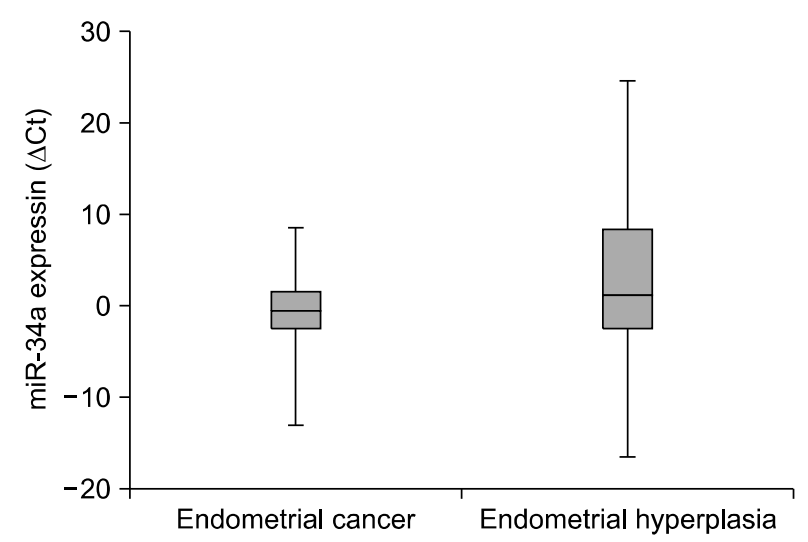

Figure 1. Comparison of miR-34a expression in simple endometrial hyperplasia and endometrial cancer tissues. The data represent the average SD of each Ct value between the duplication data for miR-34a (Endometrial cancer $-0.71 \pm 3.90$; Endometrial hyperplasia $2.68 \pm 8.62)$. 

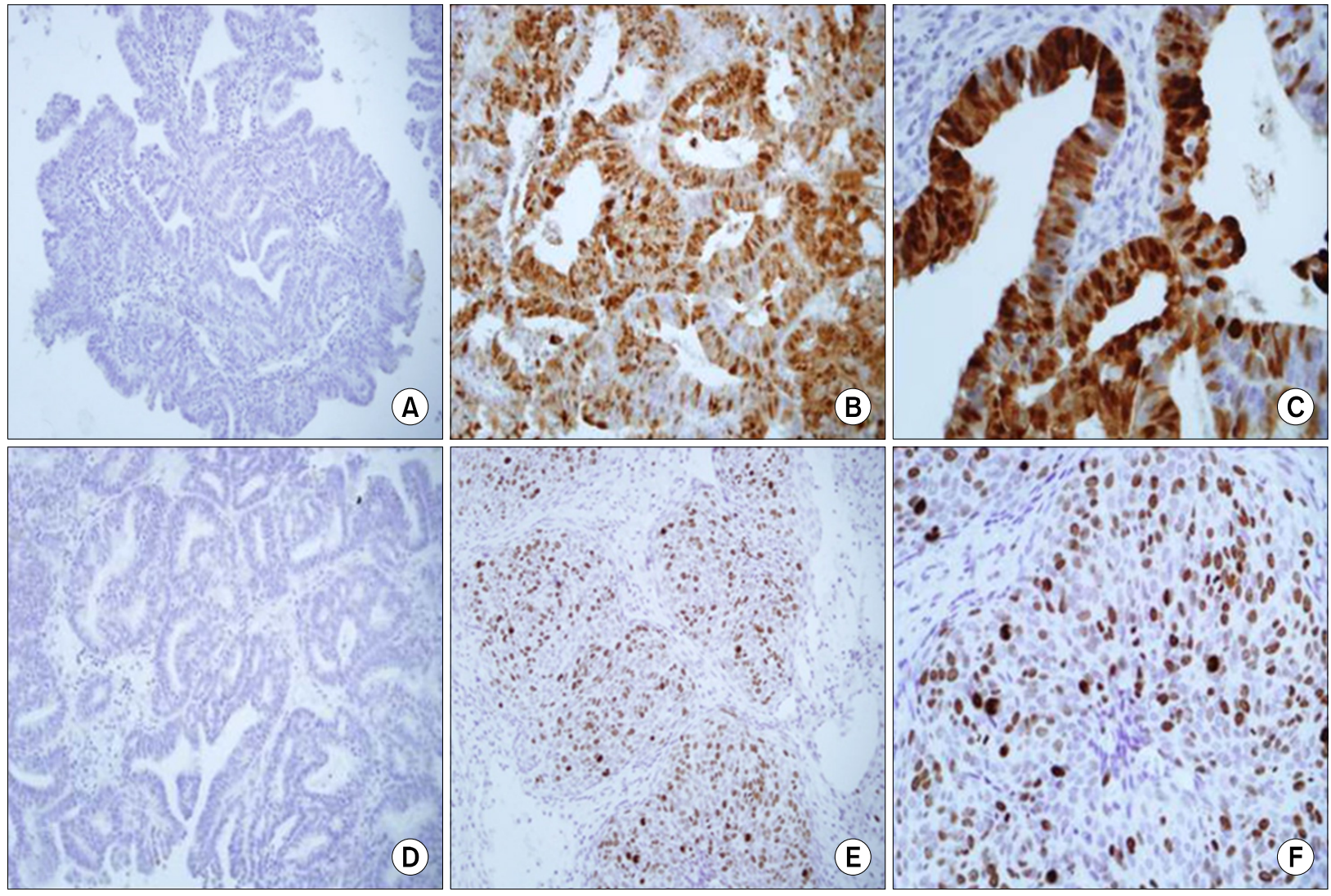

Figure 2. Immunohistochemical findings of p16 and Ki-67 in endometrial cancer tissues; p16 showed a negative immunoreactivity (A, $\times 100$ ) p16 showed a positive nuclear and cytoplasmic immunoreactivity $(B, \times 200 ; C, \times 400)$. Ki-67 showed a negative immunoreactivity (D, $\times 100)$, Ki-67 showed a positive nuclear immunoreactivity (E, $\times 200 ; \mathrm{F}, \times 400)$.

Table 2. Relationship between expression of miR-34a and p16 and Ki-67 in endometrial cancers

\begin{tabular}{|c|c|c|c|c|c|c|}
\hline \multirow{2}{*}{ Expression } & \multicolumn{2}{|c|}{ p16 protein } & \multirow{2}{*}{$P$-value } & \multicolumn{2}{|c|}{ Ki-67 protein } & \multirow{2}{*}{$P$-value } \\
\hline & Positive & Negative & & Positive & Negative & \\
\hline miR-34a & - & - & & - & - & \\
\hline Under & $15(62.5)$ & $9(37.5)$ & NS & $17(70.8)$ & $7(29.2)$ & NS \\
\hline Over & $10(90.9)$ & $1(9.1)$ & & $10(90.9)$ & $1(9.1)$ & \\
\hline
\end{tabular}

Values are presented as number (\%).

a potential biomarker for endometrial cancer diagnosis.

Recent studies suggest that miRs may modulate gene expression leading to translational repression and mRNA cleavage. ${ }^{26}$ For example, Malhas et al. ${ }^{29}$ reported that 16 is controlled by miR-24 and miR-31, while Giglio et al. ${ }^{30}$ reported that p16 is downregulated by miR-24 overexpression in human embryonic kidney cells. Misso et al. ${ }^{26}$ reported that an elevation of miR-34a levels reduced the expression of Ki-67 in lung tissues. Other studies have reported a significant correlation between miR expression levels and Ki-67 protein expression in breast cancer. ${ }^{24.25}$ The present study indicated a lower overexpression of $\mathrm{p} 16$ in miR-34a underexpressing $(15 / 24,62.5 \%)$ than in miR-34a overexpressing (10/11, 90.9\%) cases. Likewise, Ki-67 overexpression was lower in miR-34a underexpressing $(17 / 24,70.8 \%)$ than in miR-34a overexpressing $(10 / 11,90.9 \%)$ cases. Although not statistically significant, the frequency of 16 and Ki-67 overexpression tended to be lower in the cases underexpressing than overexpressing miR-34a, suggesting an involvement of miR-34a as a cell cycle regulator via p16 and as cell proliferation indicator via Ki-67.

The expression of miR-34a can be regulated by several mechanisms, including genomic loss, epigenetic modification, and transcriptional regulation. ${ }^{3}$ The effect of loss of the miR-34a gene which function as a tumor suppressor in human cancers, are not yet fully understood, but other studies suggest that an epigenetic mechanism and Human papillomavirus (HPV) infection are involved. Lodygin et al. ${ }^{31}$ reported that hypermethylation of $\mathrm{CPG}$ islands in the miR-34a gene promoter region was correlated with silenced expression of miR-34a in a variety of solid tumors including breast, lung, colon, kidney, bladder and pancreatic carcinomas. Hui et al. ${ }^{32}$ and Lajer et al. ${ }^{33}$ reported a 
possible link between HPV infections and miRs expression in various cancers, including cervical and endometrial cancers. Tissues infected with HPV also demonstrate reduced expression of tumor-suppressive miR-34a. ${ }^{18}$ Therefore, the importance of miR-34a is further highlighted by the many factors known to be involved in its regulation. A complex network of regulatory mechanisms results in the tissue-specific expression of miR-34a in various types of cancer, and further studies are needed.

In summary, this study was undertaken to analyze miR-34a expression by qRT-PCR in tissue samples of simple endometrial hyperplasia and endometrial cancer. This study indicated that miR-34a is involved in post transcriptional regulation, and that underexpression of miR-34a may play a role in endometrial carcinogenesis. Although not statistically significant, the frequency of p16 and Ki-67 overexpression in cases with miR-34a underexpression tended to be lower in endometrial cancers. Further studies are needed to define the relation between miR-34a expression and tissue specific protein expression.

\section{ACKNOWLEDGMENTS}

This work was supported by the Brain Busan 21 Project in 2015.

\section{CONFLICTS OF INTEREST}

No potential conflicts of interest were disclosed.

\section{REFERENCES}

1. Banno K, Kisu I, Yanokura M, Masuda K, Kobayashi Y, Ueki A, et al. Endometrial cancer and hypermethylation: regulation of DNA and microRNA by epigenetics. Biochem Res Int 2012;2012: 738274.

2. Lee TS, Jeon HW, Kim YB, Kim YA, Kim MA, Kang SB. Aberrant microRNA expression in endometrial carcinoma using formalin-fixed paraffin-embedded (FFPE) tissues. PLoS One 2013;8: e81421.

3. Li XJ, Ren ZJ, Tang JH. MicroRNA-34a: a potential therapeutic target in human cancer. Cell Death Dis 2014:5:e1327.

4. Ramón LA, Braza-Boïls A, Gilabert J, Chirivella M, España F, Estellés A, et al. microRNAs related to angiogenesis are dysregulated in endometrioid endometrial cancer. Hum Reprod 2012;27: 3036-45.

5. Chung TK, Cheung TH, Huen NY, Wong KW, Lo KW, Yim SF, et al. Dysregulated microRNAs and their predicted targets associated with endometrioid endometrial adenocarcinoma in Hong Kong women. Int J Cancer 2009;124:1358-65.

6. Qin X, Yan L, Zhao X, Li C, Fu Y. microRNA-21 overexpression contributes to cell proliferation by targeting PTEN in endometrioid endometrial cancer. Oncol Lett 2012;4:1290-6.

7. Yanokura M, Banno K, Kobayashi Y, Kisu I, Ueki A, Ono A, et al.
MicroRNA and endometrial cancer: roles of small RNAs in human tumors and clinical applications (review). Oncol Lett 2010;1:935-40.

8. Chen X. A microRNA as a translational repressor of APETALA2 in Arabidopsis flower development. Science 2004;303:2022-5.

9. Poy MN, Eliasson L, Krutzfeldt J, Kuwajima S, Ma X, Macdonald $\mathrm{PE}$, et al. A pancreatic islet-specific microRNA regulates insulin secretion. Nature 2004:432:226-30.

10. Gilabert-Estelles J, Braza-Boils A, Ramon LA, Zorio E, Medina P, Espana F, et al. Role of microRNAs in gynecological pathology. Curr Med Chem 2012;19:2406-13.

11. Ohlsson Teague EM, Van der Hoek KH, Van der Hoek MB, Perry $\mathrm{N}$, Wagaarachchi P, Robertson SA, et al. MicroRNA-regulated pathways associated with endometriosis. Mol Endocrinol 2009;23: 265-75.

12. Ramón LA, Braza-Boïls A, Gilabert-Estellés J, Gilabert J, España F, Chirivella $\mathrm{M}$, et al. MicroRNAs expression in endometriosis and their relation to angiogenic factors. Hum Reprod 2011:26:108290.

13. Zorio E, Medina P, Rueda J, Millán JM, Arnau MA, Beneyto M, et al. Insights into the role of microRNAs in cardiac diseases: from biological signalling to therapeutic targets. Cardiovasc Hematol Agents Med Chem 2009; 7:82-90.

14. Nicoloso MS, Spizzo R, Shimizu M, Rossi S, Calin GA. MicroRNAs--the micro steering wheel of tumour metastases. Nat Rev Cancer 2009;9:293-302.

15. Le XF, Merchant O, Bast RC, Calin GA. The roles of microRNAs in the cancer invasion-metastasis cascade. Cancer Microenviron 2010;3:137-47.

16. Lee JW, Park YA, Choi JJ, Lee YY, Kim CJ, Choi C, et al. The expression of the miRNA-200 family in endometrial endometrioid carcinoma. Gynecol Oncol 2011;120:56-62.

17. Lee H, Choi HJ, Kang CS, Lee HJ, Lee WS, Park CS. Expression of miRNAs and PTEN in endometrial specimens ranging from histologically normal to hyperplasia and endometrial adenocarcinoma. Mod Pathol 2012;25:1508-15.

18. Li B, Hu Y, Ye F, Li Y, Lv W, Xie X. Reduced miR-34a expression in normal cervical tissues and cervical lesions with high-risk human papillomavirus infection. Int J Gynecol Cancer 2010;20:597-604.

19. Ignatov A, Bischoff J, Schwarzenau C, Krebs T, Kuester D, Herrmann $\mathrm{K}$, et al. P16 alterations increase the metastatic potential of endometrial carcinoma. Gynecol Oncol 2008;111:365-71.

20. Giordano G, Azzoni C, D'Adda T, Merisio C. P16(INK4a) overexpression independent of Human Papilloma Virus (HPV) infection in rare subtypes of endometrial carcinomas. Pathol Res Pract 2007;203:533-8.

21. Oreskovic S, Babic D, Kalafatic D, Barisic D, Beketic-Oreskovic L. A significance of immunohistochemical determination of steroid receptors, cell proliferation factor Ki-67 and protein p53 in endometrial carcinoma. Gynecol Oncol 2004:93:34-40.

22. Stratigos AJ, Kapranos N, Petrakou E, Anastasiadou A, Pagouni A, Christofidou E, et al. Immunophenotypic analysis of the p53 gene in non-melanoma skin cancer and correlation with apoptosis and cell proliferation. J Eur Acad Dermatol Venereol 2005:19:180-6.

23. Ueda T, Aozasa K, Tsujimoto M, Ohsawa M, Uchida A, Aoki Y, et al. Prognostic significance of Ki-67 reactivity in soft tissue sarcomas. Cancer 1989:63:1607-11.

24. Rask L, Balslev E, Jørgensen S, Eriksen J, Flyger H, Møller S, et al. 
High expression of miR-21 in tumor stroma correlates with increased cancer cell proliferation in human breast cancer. APMIS 2011;119:663-73.

25. Lee C, He H, Jiang Y, Di Y, Yang F, Li J, et al. Elevated expression of tumor miR-222 in pancreatic cancer is associated with Ki67 and poor prognosis. Med Oncol 2013;30:700.

26. Misso G, Di Martino MT, De Rosa G, Farooqi AA, Lombardi A, Campani V, et al. Mir-34: a new weapon against cancer? Mol Ther Nucleic Acids 2014:3:e194.

27. Han C, Yu Z, Duan Z, Kan Q. Role of microRNA-1 in human cancer and its therapeutic potentials. Biomed Res Int 2014:2014: 428371.

28. Banno K, Yanokura M, Kisu I, Yamagami W, Susumu N, Aoki D. MicroRNAs in endometrial cancer. Int J Clin Oncol 2013;18:18692.

29. Malhas A, Saunders NJ, Vaux DJ. The nuclear envelope can con- trol gene expression and cell cycle progression via miRNA regulation. Cell Cycle 2010;9:531-9.

30. Giglio S, Cirombella R, Amodeo R, Portaro L, Lavra L, Vecchione A. MicroRNA miR-24 promotes cell proliferation by targeting the CDKs inhibitors p27Kip1 and p16INK4a. J Cell Physiol 2013;228: 2015-23.

31. Lodygin D, Tarasov V, Epanchintsev A, Berking C, Knyazeva T, Körner $\mathrm{H}$, et al. Inactivation of miR-34a by aberrant $\mathrm{CpG}$ methylation in multiple types of cancer. Cell Cycle 2008;7:2591-600.

32. Hui $\mathrm{AB}$, Lin $\mathrm{A}, \mathrm{Xu} \mathrm{W}$, Waldron $\mathrm{L}$, Perez-Ordonez B, Weinreb I, et al. Potentially prognostic miRNAs in HPV-associated oropharyngeal carcinoma. Clin Cancer Res 2013;19:2154-62.

33. Lajer CB, Garnæs E, Friis-Hansen L, Norrild B, Therkildsen MH, Glud $\mathrm{M}$, et al. The role of miRNAs in human papilloma virus (HPV)-associated cancers: bridging between HPV-related head and neck cancer and cervical cancer. Br J Cancer 2012;106:1526-34. 